\title{
11 Social Network Approaches to Bullying and Victimization
}

René Veenstra \& Gijs Huitsing

Please cite as:

Veenstra, R., \& Huitsing, G. (2021). Social network approaches to bullying and victimization.

In P. K. Smith, \& J. O’Higgins Norman (eds.). The Wiley Blackwell Handbook of Bullying.

Volume 1 (pp. 196-214). Hoboken, NJ: Wiley.

Bullying is by nature a group phenomenon. Therefore, it is important to study the network in which the bullying occurs. Relationships between victims and bullies do not occur in isolation, but exist in larger networks and in interplay with other relationships. Increasingly, researchers are collecting rich data on relationships in childhood and adolescence through network questions (Cillessen \& Bukowski, 2018; Veenstra, Dijkstra, Steglich, \& Van Zalk, 2013; even from 6-years on: Verlinden et al., 2014). This includes data on bullying (who do you bully?), victimization (by whom are you bullied?), and defending (by whom are you defended?) as well as other relationships, such as friendships (who are your best friends?) and dislike (who do you dislike?).

To obtain an accurate impression of relationships in networks, it is important to collect complete network data about the presence and absence of relationships among a naturally bounded group (e.g., children in a class, grade, or school), as well as their behaviors. This requires that children report on their own relationships. Network questions on bullying ("Who do you bully?”) and victimization (“By whom are you bullied?) provide children's own perspective on their relationships in the network (e.g., a class, grade, or school), and together they provide information on all the network relationships. These network questions are in contrast to reputational peer nominations that are often used in peer research, in which 
children are, for example, asked "Which classmates bully others?" or "Which classmates are bullied by others?” (see, e.g., Cillessen \& Bukowski, 2018). Such peer nominations provide insights into the perceived behavior or reputation of children, but do not contain relational information (e.g., when children are nominated as bullies, it is not known which and how many classmates they bully).

In this chapter we discuss the increasing number of studies on bullying from a network perspective. In the first part, we discuss cross-sectional network studies on bullying. In the second part, we introduce the rationale and the preconditions for longitudinal social network analyses. In the third part, we discuss all studies that employed a longitudinal social network perspective, including studies that examine the dynamics in friendships and bullying behavior. We also discuss new directions in (longitudinal) social network analyses on bullying and victimization, including studies that examine relationships between bullies, victims, and defenders. The chapter ends with the potential for network interventions.

\section{Cross-sectional social network analysis}

One of the first social network studies on bullying and victimization (Veenstra et al., 2007) examined who bullies whom, looking at this relationship from the perspective of both the bully and the victim, using a cross-sectional, multilevel $p 2$ model (Zijlstra, Van Duijn, \& Snijders, 2006). The $p 2$ model uses the dyad as dependent variable, and controls for dependencies in the network data: differences in nominating (nominator variance) and receiving nominations (target variance), reciprocity, and density between the networks. Results showed that, at the dyadic level, bullies had an advantage over their specific victims by being more dominantly aggressive. Bullies specifically picked on targets who were rejected by peers, which might be part of the bully's strategy not to lose social approval (Veenstra et al., 2007, see also Rodkin \& Berger, 2008). The findings from the victim's perspective were highly complementary and revealed a differential in aggressiveness and 
vulnerability between victims and bullies (Veenstra et al., 2007). As such, this study demonstrated the importance of the power imbalance in favor of bullies over victims (Volk, Dane, \& Marini, 2014).

Another early study, using the same $p 2$ model, investigated the extent to which bullies and victims differ in how important status is to them and the extent to which they are perceived as popular (Sijtsema, Veenstra, Lindenberg, \& Salmivalli, 2009). As predicted, bullies found status important and were high on perceived popularity. In contrast, victims found status less important, were only reactively aggressive, and low on perceived popularity. That study also showed that being popular is not the same as being liked, because bullies were just as rejected by their classmates as victims were. Furthermore, eighth-grade bullies found status more important than fourth-grade bullies, possibly indicating that striving for status increases in early adolescence. Another $p 2$ study investigated bullying in ethnically heterogeneous schools, and found that both inter-ethnic and intra-ethnic bullying increase when the level of ethnic diversity increases in schools (Tolsma, Van Deurzen, Stark, \& Veenstra, 2013, see for another network study on majority-minority bullying: Kisfalusi, Pál, \& Boda, 2020).

The $p 2$ model was also used to examine who defends whom and found that defending took place predominantly among same-sex peers, that defenders were especially liked by the victims they defended, and that defenders had a high status among not only victims but also other classmates (Sainio, Veenstra, Huitsing, \& Salmivalli, 2011).

An extension of the $p 2$ model is the $p^{*}$ or Exponential Random Graph Model (ERGM, Lusher, Koskinen, \& Robins, 2013). This examines relationships beyond the dyad, by investigating dyadic, triadic (referring to relationships between three persons), and higherorder level effects (referring to relationships between four or more persons). One such study examined victim-defender relationships and found that victims were likely to be defended by 
students whom they perceive as friends or whom perceive them as friends (Oldenburg, Van Duijn, \& Veenstra, 2018). Victimized students were unlikely to be defended by classmates whom they disliked or who indicated to dislike them. Triadic effects showed that defending was more likely to occur when the victim and (potential) defender had the same friends, and that defending was likely to occur between students who disliked the same classmates (Oldenburg et al., 2018).

Earlier cross-sectional studies using ERGMs investigated the interplay between bullying and positive relationships such as general liking (Huitsing et al., 2012) and defending relationships (Huitsing \& Veenstra, 2012). These studies showed that not only victims but also bullies liked or defended each other. Bullies tended to like or defend other bullies who targeted at the same peers. In that way, bullies created an ingroup of bullies and an outgroup of victims. The embeddedness among a group of bullies might protect them from retaliation by victims. A descriptive analysis of a typical network showed that especially the group of bullies were highly popular (Huitsing \& Veenstra, 2012). Although victims are usually in great need of defending, they were somewhat less likely to seek each other's support than bullies did. Victims might fear that siding with other weak and powerless victims is damaging for their social position. These findings were replicated in early childhood, where aggressors defended other aggressors when targeting the same victim (Huitsing \& Monks, 2018).

Social network studies can also be used to examine agreement on who bullies whom (Ahn, Rodkin, \& Gest, 2013; Huitsing et al., 2019; Oldenburg et al., 2015). In a multilevel study (Oldenburg et al., 2015), it was investigated to what extent students who according to their self-reports were not victimized (referred to as reporters), gave victimization nominations to classmates who according to their self-reports were victimized (referred to as receivers). There was more reporter-receiver agreement in same-sex dyads, especially when both the reporter and receiver were boys. Furthermore, reporters who behaved as outsiders 
during bullying episodes were less likely to agree on the receiver's self-reported victimization and, by contrast, reporters who behaved as defenders during bullying episodes were more likely to agree on the victimization. Finally, the results showed that reporters gave more victimization nominations to receivers who were victimized (very) often than to receivers who were victimized sometimes. In another study (Tatum \& Grund, 2020), adolescents were asked whom they were mean to (confession networks) and who were mean to them (accusation networks; see also: Faris \& Ennett, 2012). When females confessed to be mean, others were less likely to match their confession. Additionally, adolescents who feel worried were more likely to agree when others reported to be mean to them.

A few social network studies have been done with children in kindergarten or early elementary school. Considering agreement, higher concordance was found on victimaggressor relationships between self- and peer-reports than between one of these and teacher reports (Huitsing et al, 2019). Generally, the agreement between different informants was relatively low when concordance for specific victim-bully relationships was investigated. On the child level, the agreement was higher, suggesting that informants agreed more on who is victimized and who is bullied, rather than specifically on who is victimized by whom. According to self and peer reports, boys as well as girls were victimized by boys and girls equally. Teachers perceived less victimization among girls, because they reported less crosssex victimization (in particular that girls are victimized by boys) than same-sex victimization. Other studies on same- and cross-sex bullying found that, in line with research on older samples (Sainio et al., 2011; Sainio, Veenstra, Huitsing, \& Salmivalli, 2012; Veenstra et al., 2007), boys in early childhood were more aggressive than girls, toward both sexes, and that defending was sex-segregated (Huitsing \& Monks, 2018). Studies in early childhood that investigated child characteristics found that teacher-rated dominance was related to not only aggression but also to victimization, whereas teacher-rated insecurity was related to less 
aggression (Huitsing \& Monks, 2018).

\section{Longitudinal social network analysis}

A limitation of these aforementioned studies was, however, that they were cross-sectional. Cross-sectional data only allow us to determine the extent to which children are bullying others and the characteristics associated with their involvement, but not to examine why this is the case. Longitudinal social network analysis, however, allows us to combine information about relationships with their behaviors (e.g., bullying, either on the individual level or even on the relationship level), which provides insights into why individuals are inclined to associate with similar others (McPherson, Smith-Lovin, \& Cook, 2001). There are three explanations for the emergence of this similarity principle: selection, opportunity, and influence.

Beginning in early childhood, children tend to select peers as friends who are more or less similar to themselves. Similarity fosters agreement in behaviors, characteristics, and attitudes, which makes communication easier and contributes to trust in each other, enabling individuals to communicate with less effort and with shared feelings of understanding and belongingness. This makes these relationships more rewarding and stable, and reduces conflicts (Byrne, 1971). Shared characteristics also provide a source of validation for development and reinforcement of social identity (Hallinan, 1980). Similarity between friends is therefore an important basis for initiating or maintaining friendships.

Peer selection is not only steered by preferences, but also depends on the composition of the pool of potential friends, which structures and restricts choices (Blau, 1977). There must be an opportunity to meet each other. As schools tend to have a strong degree of homogeneity between children (e.g., in terms of intelligence, socioeconomic status, and ethnicity), the chances of meeting and affiliating with similar peers are high. Similarity of friends may, therefore, be the result of opportunity structures to meet similar others (Lomi \& 
Stadtfeld, 2014; Rivera, Soderstrom, \& Uzzi, 2010).

Peer selection and opportunity structures have an impact on influence processes in which individuals adopt their friends' behaviors, characteristics and attitudes, resulting in peer group homogeneity (Cohen, 1977; Friedkin, 1998). Influence processes might work via mechanisms of social learning and imitation (Bandura, 1977), expected rewards of conformity (Burgess \& Akers, 1966), social facilitation (Zajonc, 1968), or peer pressure (Warr, 2002). Thus, similarity between friends may be the result not only of selection but also of influence (or socialization) processes, referring to the tendency of individuals to become more similar to one another in response to the behaviors, characteristics, or attitudes of their friends.

The methodological challenge is that selection, opportunity, and influence processes might result in the same empirical phenomenon: similarity between friends. Given the opportunity to meet, similar individuals may connect to each other (selection), which suggests that behavior remains similar, but relationships change, or connected individuals may become increasingly similar (influence), which suggests that relationships remain stable but behavior changes. The investigation of these interwoven social processes puts a high demand on research design and associated methodology.

Longitudinal social network analysis using stochastic actor-based modeling (Snijders, Van de Bunt, \& Steglich, 2010) is particularly suitable to help disentangle these interwoven processes by studying the dynamics of networks and behaviors. This method requires longitudinal data about all individuals in a network and their changes in relationships and behaviors. Longitudinal data allow us to examine whether similarity in behavior occurs because children who were already similar formed or maintained friendships (selection), or that friends became more similar in their behavior, characteristics, or attitudes over time (influence).

Longitudinal network data can be analyzed with stochastic actor-based models, 
implemented in the RSiena program (Ripley, Snijders, Boda, Vörös, \& Preciado, 2019). RSiena (Simulation Investigation for Empirical Network Analysis, in the R-package) was developed to model network and behavior dynamics as two interdependent processes, taking unobserved changes between observation moments into account to avoid overestimation. The unobserved change process is assumed to take place as gradually as possible, by 'microsteps' that consist of either a change in a relationship or a step up or down on the behavior scale. Due to the unobserved nature of the exact sequence of changes connecting observation moments, simulation-based inference becomes necessary to estimate model parameters (Snijders et al., 2010).

Longitudinal social network analysis allows us to separate selection and influence processes by estimating how both processes contribute to the observed similarity among connected children (Veenstra \& Steglich, 2012). It allows us to assess the effect of behavior on the formation of relationships (selection effects) and the effect of behavior of affiliated peers on individual behavior (influence effects), while controlling for structural network effects (e.g., reciprocity and transitivity) and behavioral tendencies (for example, the tendency of actors in the network to regress to the mean or to polarize in behavior), see Figure 11.1. Many social network studies using stochastic actor-based models have separated selection and influence processes for externalizing problems (aggression, delinquency), internalizing problems (anxiety, depression, loneliness), substance use (drinking, smoking, marijuana use), and school behavior (for overviews see: Veenstra, Dijkstra, \& Kreager, 2018; Veenstra et al., 2013).

\section{Dynamics in networks and bullying and victimization}

So far, twelve studies, from seven countries, examined selection and influence processes related to bullying, victimization, defending, or moral disengagement, see Table 11.1. The studies among younger children usually collected networks among classmates (with the 
number of classes varying from 5 to 26 and as outlier a Finnish study containing 686 classes), whereas the studies in adolescence usually collected networks among grade-mates (with the number of settings varying from 2 to 7 ) or among all students in one small middle school (with 190 students). A Finnish study (Sentse, Kiuru, Veenstra, \& Salmivalli, 2014) contained more than 9,000 respondents. The other studies were all smaller than 750 students. All studies had two or three waves of data, with an interval between the waves of five to twelve months. The networks were most often based on best or (closest) friend nominations, although some studies collected data on who hangs out with whom, who likes whom most, or on who is defended by whom. The nominations were often unlimited or with a maximum number of nominations given up to 18 or 20 . In two studies the friendship choice was quite restricted, up to five (Caravita, Sijtsema, Rambaran, \& Gini, 2014) or eight (Merrin et al., 2018) friends. The response rate was in most studies $80 \%$ or higher in each network, but lower in two studies (Sentse, Dijkstra, Salmivalli, \& Cillessen, 2013: 62-68\%; Sijtsema, Rambaran, \& Ojanen, 2013: 70-85\%).

Bullying. Selection and influence processes have been investigated with respect to bullying. Three studies have by far the most power because of an exceptionally large sample (Sentse et al., 2014) or because they included relational information about bullying (Huitsing, Snijders, Van Duijn, \& Veenstra, 2014; Rambaran, Dijkstra, \& Veenstra, 2020). All three studies provided evidence for selection similarity as well as influence effects in bullying. One study investigated selection and influence processes with respect to homophobic teasing (Merrin et al., 2018), and found that similarity in homophobic teasing was due to both selection and influence effects.

Victimization. Selection and influence processes have been investigated with respect to victimization. Research in childhood generally does not find that friendships are based on similarity in victimization or that friends influence each other's level of victimization (Berger, 
Gremmen, Palacios, \& Franco, 2019; Rambaran, Dijkstra et al., 2020), although one study found that defenders of victims in one school ran the risk of becoming victimized, thus, being “influenced" to take upon the role of victim (Huitsing et al., 2014). However, research in adolescence provides evidence for selection on the basis of general victimization (Lodder, Scholte, Cillessen, \& Giletta, 2016), physical victimization (Sentse et al., 2013), or relational victimization (Sijtsema et al., 2013). These studies also show that there is an influence of friend's general victimization (Lodder et al., 2016), physical victimization (Sijtsema et al., 2013), and relational victimization (Sentse et al., 2013; Sijtsema et al., 2013).

Defending. Selection and influence processes with respect to defending were examined in three samples. Among 9-years-olds, there was no evidence for selection based on defending, but among early adolescents such a selection effect was found (Caravita et al., 2014), in particular for girls (Ruggieri, Friemel, Sticca, Perren, \& Alsaker, 2013). Friend's defending behavior also had an influence in early adolescence, but not in childhood (Caravita et al., 2014).

Moral Disengagement. Two studies investigated selection and influence processes with respect to moral disengagement (Caravita et al., 2014; Sijtsema, Rambaran, Caravita, \& Gini, 2014). Caravita and colleagues (2014) found no evidence for selection on moral disengagement, either among 9-years-olds or among 12-years-olds. A direct influence effect of friends' moral disengagement was found in early adolescence (Caravita et al., 2014). In addition, moral disengagement moderated influence effects on bullying. Influence on bullying was stronger for early adolescents when they had higher levels of moral disengagement (Sijtsema et al., 2014).

\section{New directions in social network dynamics in bullying and victimization}

There are also important contextual effects on bullying relationships, that are often conceptualized as social norms (Veenstra et al., 2018), which is the consensus on appropriate 
behavior in a specific context. Longitudinal social network analysis allows us to examine whether selection and influence effects depend on the (perceived) norms in a classroom. In an exemplary study by Shin (2020), it was found that the perceived bullying norms moderated friendship selection on bullying as well as friendship influence on both bullying and victimization. When adolescents perceived bullying norms to be positive, bullying behaviors were more likely to be used as a friendship selection criterion and adolescents who highly bully others had a higher tendency to select high bullying peers as friends. In addition, as adolescents perceived higher bullying norms, friendship influence on bullying and victimization was magnified. Anticipating positive consequences of bullying, bullies seem to be more likely to adopt the bullying behavior of their high bullying friends and engage in bullying even more frequently. When adolescents perceived that their classmates condone bullying, they would be less likely to act on their empathy or to intervene for or defend the victims because of their increased concerns over being the potential future targets of bullies. Accordingly, when youth perceived bullying norms as positive, victimization experiences were more severe and friendship influence on victimization was stronger (Shin, 2020).

Another study by Sentse and colleagues (2014), using data of the evaluation study of the Finnish KiVa anti-bullying program, explored whether the social network dynamics in bullying differed between intervention and control schools. It was examined whether adolescents at intervention and control schools differed in the tendency to (1) like peers who engage in bullying, (2) like each other on the basis of similarity in bullying, and (3) be resistant to the influence of peers who engage in bullying. However, no significant differences between intervention and control schools were found for those effects.

A limitation of the studies in Table 11.1 (with two exceptions: Huitsing et al., 2014; Rambaran, Dijkstra et al., 2020) was that bullying and victimization were considered as individual characteristics, omitting relational information about bullying. That problem was 
addressed in longitudinal social network studies investigating the co-development of bullying/ victimization and defending relationships (Huitsing et al., 2014) as well as friendships (Rambaran, Dijkstra et al., 2020). Those longitudinal studies took as a starting point the similarity between victims (see Figure 11.2.c, with victims being victimized by the same bully being positively associated through defending or friendship) and similarity between bullies (see Figure 11.3.c, with bullies targeting the same victim being positively associated through defending or friendships). The question is whether selection or influence leads to this similarity in network position. In the study on defending between victims (Huitsing et al., 2014), in two of the three analyzed school networks, victims selected each other in defending to seek support for protection against bullies (Figure 11.2.a $\rightarrow$ Figure 11.2.c). In one of the three schools, there was evidence for influence, meaning that defenders of victims run the risk of becoming victimized by the bully of the defended victims (Figure 11.2.b $\rightarrow$ Figure 11.2.c). The other study with friendships as the positive relation between victims found no evidence for selection or influence effects on victimization (Rambaran, Dijkstra et al., 2020).

Figure 11.3 shows the situation for similarity in bullying. For these mechanisms, it was found that there was selection for both defending (one of the three schools in Huitsing et al., 2014) and friendships (Rambaran, Dijkstra et al., 2020). This suggests that bullies seek other bullies to collectively target victims (Figure 11.3.a $\rightarrow$ Figure 11.3.c). Moreover, the strongest effects were found for influence among bullies, both for defending (in all three schools of Huitsing et al., 2014) and friendships (Rambaran, Dijkstra et al., 2020). An explanation is that "defenders of bullies" assisted bullies first, but then are influenced to turn their aggression also to the victims (Figure 11.3.b $\rightarrow$ Figure 11.3.c). A recent study documented that the friendships between bullies were more likely for same-sex than for crosssex bullies (Hooijsma et al, 2020). Other studies on negative relations (general dislike: "Who do you dislike") also found evidence for influence effects, suggesting that, over time, friends 
had a tendency to agree about whom to dislike (Berger \& Dijkstra, 2013; Pál, Stadtfeld, Grow, \& Takács, 2016; Rambaran, Dijkstra, Munniksma, \& Cillessen, 2015). Interestingly, adolescents also have a tendency to dislike peers who others perceive as popular but they themselves do not look up to (Pál et al., 2016). Such a tendency to nonconformity might be the result of frustration about status attribution processes.

Another innovative study, by Van der Ploeg, Steglich, \& Veenstra (2020), examined the co-development of bullying and popularity, and found that bullying generally increased peer status among classmates, and that high status individuals tend to bully. When differentiating between the creation and maintenance of specific ties, it was found that unlike low-status bullies, high-status bullies discontinued bullying the same victims, but replaced those with new victims. Furthermore, when looking into the age-dependency of these effects, it was shown that bullying was rewarded by peer status attributions only for the higher grades of elementary school. Children in grade 2 even sanctioned bullying by a withdrawal of status attributions. These findings reiterated that bullying is a complex group phenomenon in which obtaining and maintaining high social standing plays a decisive role (Salmivalli, 2010; Volk et al., 2014), and that a network perspective deepens our understanding of the interplay between bullying and peer status.

Another study did not provide evidence that victimization depended on age differences between children (Rambaran, Van Duijn, Dijkstra, \& Veenstra, 2019). That study also did not indicate that children in multi-grade classrooms are better or worse off in terms of victimbully relationships than children in single-grade classrooms. A related study found that school and classroom stability and change have a minor impact on the formation of victim-bully relationships between children (Rambaran, Van Duijn, Dijkstra, \& Veenstra, 2020). Bullying relationships were found to develop most easily between children in the same grade, more so in stable classrooms than in classrooms with changing classroom composition, with no clear 
evidence that newcomers are more at risk of becoming victimized.

\section{Toward network interventions}

Increased knowledge on dynamics in bullying and victimization relationships can provide insights for direct interventions. Whether selection, influence, or both play a role in the development of bullying, victimization, defending, or moral disengagement has implications for the design of interventions. Social network information can also be used to formulate advice for individual teachers (Kaufman, Huitsing, Bloemberg, \& Veenstra, 2021). Advice on who is connected to whom (both positively, e.g., friendships and defending, or negatively, e.g., bullying or disliking), given to teachers, will provide them with suggestions on where and how to intervene. Information on network structures or aggregates of relationships (implying how often children are nominated for bullying, victimization, or defending) potentially fosters the understanding of group processes in bullying, helps to detect children with a marginalized network position (e.g., having few friends or being highly disliked), and helps to identify children who might function as role models because they are considered as highly popular or as being a good leader (Andrews, 2020).

Network interventions can be applied at different levels (Valente, 2012). First, interventions may be aimed at individuals with a central or influential position in the network. For example, in some interventions central adolescents are employed as role models to set the norm and influence the behavior of other students (Paluck, Shepherd, \& Aronow, 2016). Second, interventions may aim to alter relationship patterns. For example, an intervention may try to alter friendship networks in ways that reduce the potential for peer influence toward problem behaviors (Rulison, Gest, \& Osgood, 2015). Third, interventions may aim to activate relationships between individuals. For example, an intervention may try to create a friendship between two lonely children who, according to the network information, would like each other or between children who dislike each other by placing them closer in the 
classroom (Van den Berg, Segers, \& Cillessen, 2012). Fourth, interventions may aim to change the entire network structure, for example, by adding or removing actors or relationships. For example, an intervention may promote positive interpersonal relationships among minority and majority group students (Stark \& Flache, 2012).

These insights on network interventions might lead to novel research on understanding the co-evolution of youth's relationships and behaviors. The peer context has great potential for interventions (Rulison et al., 2015). The power of peers is used in several peer-based interventions, including peer support, peer leadership, and peer group programs. Social network analysis can strengthen these interventions, because interventions may be more effective if they do not target all group members, but are directed toward children with an influential network position. This is also consistent with social norms research, which reveals that behavior of popular peers is more important for imitation than the average behaviors of peers (Dijkstra, Lindenberg, \& Veenstra, 2008; Peets, Pöyhönen, Juvonen, \& Salmivalli, 2015). Lastly, evaluation of interventions may benefit from a network perspective, because it helps us to find out if and how changes in relationships explain the effectiveness of an intervention.

\section{Conclusions}

Social network research is the way to examine bullying as a group process. It requires data on relationships between children and adolescents through network questions. Cross-sectional network studies allow us to examine who bullies whom or who defends whom, as well as the agreement on these dyadic relationships. Longitudinal network studies allow us to particularly examine selection and influence processes. The longitudinal studies with the most power have shown that selection and influence processes play a role for bullies. For victims, selection and influence processes have been found in adolescence (secondary education), but not in childhood (elementary education). Social network dynamics in bullying and victimization can 
also be linked to research on the impact of social norms or the evaluation of an intervention. Recent studies have also started to examine interdependencies between multiple positive and negative relationships. For example, between bullying (who bullies whom?) and defending (who defends whom?) or friendships (who is befriended with whom?), or between bullying and popularity (who nominates whom as popular?). Most social network research on bullying and victimization has been done in late childhood or early adolescence. A few studies, however, have shown that it is also feasible to examine network-behavior dynamics at younger ages. Further research is necessary on whether and how individuals in a network, relationship patterns, or the entire network structure can be targeted by interventions. Social network insights may contribute to the effectiveness of peer-based interventions because it allows us to examine detailed selection and influence processes.

\section{References}

Ahn, H. J., Rodkin, P. C., \& Gest, S. D. (2013). Teacher-student agreement on "bullies and kids they pick on" in elementary school classrooms: Gender and grade differences. Theory into Practice, 52, 257-263. https://doi.org/10.1080/00405841.2013.829728

Andrews, N. C. Z. (2020). Prestigious youth are leaders but central youth are powerful: What social network position tells us about peer relationships. Journal of Youth and Adolescence, 49, 631-644. https://doi.org/10.1007/s10964-019-01080-5

Bandura, A. (1977). Social Learning Theory. Englewood Cliffs, NJ: Prentice Hall.

Berger, C., \& Dijkstra, J. K. (2013). Competition, envy, or snobbism? How popularity and friendships shape antipathy networks of adolescents. Journal of Research on Adolescence, 23, 586-595. https://doi.org/10.1111/jora.12048

Berger, C., Gremmen, M., Palacios, D., \& Franco, E. (2019). “Would you be my friend?”: Friendship selection and contagion processes of early adolescents who experience victimization. Journal of Early Adolescence, 39, 1286-1310. 
https://doi.org/10.1177/0272431618824753

Blau, P. M. (1977). A macrosociological theory of social structure. American Journal of Sociology, 83, 26-54.

Burgess, R. L., \& Akers, R. L. (1966). A differential association-reinforcement theory of criminal behavior. Social Problems, 14, 128-147.

Byrne, D. E. (1971). The attraction paradigm. New York: Academic.

Caravita, S. C. ., Sijtsema, J. J., Rambaran, J. A., \& Gini, G. (2014). Peer influences on moral disengagement in late childhood and early adolescence. Journal of Youth and Adolescence, 43, 193-207. https://doi.org/10.1007/s10964-013-9953-1

Cillessen, A. H. N., \& Bukowski, W. M. (2018). Sociometric perspectives. In W. M.

Bukowski, B. Laursen, \& K. H. Rubin (Eds.), Handbook of Peer Interactions, Relationships, and Groups (pp. 64-83). New York, NY: Guilford.

Cohen, J. M. (1977). Sources of peer group homogeneity. Sociology of Education, 50, 227241.

Dijkstra, J. K., Lindenberg, S., \& Veenstra, R. (2008). Beyond the class norm: Bullying behavior of popular adolescents and its relation to peer acceptance and rejection. Journal of Abnormal Child Psychology, 36, 1289-1299. https://doi.org/10.1007/s10802-0089251-7

Faris, R., \& Ennett, S. (2012). Adolescent aggression: The role of peer group status motives, peer aggression, and group characteristics. Social Networks, 34, 371-378. https://doi.org/10.1016/j.socnet.2010.06.003

Friedkin, N. E. (1998). A structural theory of social influence. Cambridge, UK: Cambridge University Press.

Hallinan, M. (1980). Patterns of cliquing among youth. In H. Foot, A. Chapman, \& J. Smith (Eds.), Friendship and social relations in children (pp. 321-342). Chichester, UK: 
Wiley.

Hooijsma, M., Huitsing, G., Kisfalusi, D., Dijkstra, J. K., Flache, A., \& Veenstra, R. (2020). Multidimensional similarity in multiplex networks: Friendships between same- and cross-gender bullies and same- and cross-gender victims. Network Science, 8, 79-96.

Huitsing, G., \& Monks, C. P. (2018). Who victimizes whom and who defends whom? A multivariate social network analysis of victimization, aggression, and defending in early childhood. Aggressive Behavior, 44, 394-405. https://doi.org/10.1002/ab.21760

Huitsing, G., Snijders, T. A. B., Van Duijn, M. A. J., \& Veenstra, R. (2014). Victims, bullies, and their defenders: A longitudinal study of the coevolution of positive and negative networks. Development and Psychopathology, 26, 645-659. https://doi.org/10.107/S0954579414000297

Huitsing, G., Van Duijn, M. A. J., Snijders, T. A. B., Perren, S., Alsaker, F. D., \& Veenstra, R. (2019). Self, peer, and teacher reports of victim-aggressor networks in kindergartens. Aggressive Behavior, 45, 275-286. https://doi.org/10.1002/ab.21817

Huitsing, G., Van Duijn, M. A. J., Snijders, T. A. B., Wang, P., Sainio, M., Salmivalli, C., \& Veenstra, R. (2012). Univariate and multivariate models of positive and negative networks: Liking, disliking, and bully-victim relationships. Social Networks, 34, 645657. https://doi.org/10.1016/j.socnet.2012.08.001

Huitsing, G., \& Veenstra, R. (2012). Bullying in classrooms: Participant roles from a social network perspective. Aggressive Behavior, 38, 494-509. https://doi.org/10.1002/ab.21438

Kaufman, T. M. L., Huitsing, G., Bloemberg, R., \& Veenstra, R. (2021). The systematic application of network diagnostics to monitor and tackle bullying and victimization in schools. International Journal of Bullying Prevention, 3, 75-87.

Kisfalusi, D., Pál, J., \& Boda, Z. (2020). Bullying and victimization among majority and 
minority students: The role of peers' ethnic perceptions. Social Networks, 60, 48-60. https://doi.org/10.1016/j.socnet.2018.08.006

Lodder, G. M. A., Scholte, R. H. J., Cillessen, A. H. N., \& Giletta, M. (2016). Bully victimization: Selection and influence within adolescent friendship networks and cliques. Journal of Youth and Adolescence, 45, 132-144. https://doi.org/10.1007/s10964-015-0343-8

Lomi, A., \& Stadtfeld, C. (2014). Social networks and social settings: Developing a coevolutionary view. KZfSS Kölner Zeitschrift Für Soziologie Und Sozialpsychologie, 66, 395-415. https://doi.org/10.1007/s11577-014-0271-8

Lusher, D., Koskinen, J., \& Robins, G. (2013). Exponential random graph models for social networks: Theory, methods and applications. Cambridge: Cambridge University Press.

McPherson, M., Smith-Lovin, L., \& Cook, J. M. (2001). Birds of a feather: Homophily in social networks. Annual Review of Sociology, 27, 415-444. https://doi.org/10.1146/annurev.soc.27.1.415

Merrin, G. J., de la Haye, K., Espelage, D. L., Ewing, B., Tucker, J. S., Hoover, M., Green, H. D. (2018). The co-evolution of bullying perpetration, homophobic teasing, and a school friendship network. Journal of Youth and Adolescence, 47, 601-618. https://doi.org/10.1007/s10964-017-0783-4

Oldenburg, B., Barrera, D., Olthof, T., Goossens, F. A., Van der Meulen, M., Vermande, M., Aleva, E., Sentse, M. \& Veenstra, R. (2015). Peer and self-reported victimization: Do non-victimized students give victimization nomiations to classmates who are selfreported victims? Journal of School Psychology, 53, 309-321. https://doi.org/10.106/j/jsp.2015.05.003

Oldenburg, B., Van Duijn, M., \& Veenstra, R. (2018). Defending one's friends, not one's enemies: A social network analysis of children's defending, friendship, and dislike 
relationships using XPNet. PLoS ONE, 13, e0194323.

https://doi.org/10.1371/journal.pone.0194323

Pál, J., Stadtfeld, C., Grow, A., \& Takács, K. (2016). Status perceptions matter:

Understanding disliking among adolescents. Journal of Research on Adolescence, 26, 805-818. https://doi.org/10.1111/jora.12231

Paluck, E. L., Shepherd, H., \& Aronow, P. M. (2016). Changing climates of conflict: A social network experiment in 56 schools. Proceedings of the National Academy of Sciences of the United States of America, 113, 566-571. https://doi.org/10.1073/pnas.1514483113

Peets, K., Pöyhönen, V., Juvonen, J., \& Salmivalli, C. (2015). Classroom norms of bullying alter the degree to which children defend in response to their affective empathy and power. Developmental Psychology, 51, 913-920. https://doi.org/10.1037/a0039287

Rambaran, J. A., Dijkstra, J. K., Munniksma, A., \& Cillessen, A. H. N. (2015). The development of adolescents' friendships and antipathies: A longitudinal multivariate network test of balance theory. Social Networks, 43, 162-176.

https://doi.org/10.1016/j.socnet.2015.05.003

Rambaran, J. A., Dijkstra, J. K., \& Veenstra, R. (2020). Bullying as a group process in childhood: A longitudinal social network analysis. Child Development, 91, 1336-1352. https://doi.org/10.1111/cdev.13298

Rambaran, J. A., Van Duijn, M. A. J., Dijkstra, J. K., \& Veenstra, R. (2019). Peer victimization in single-grade and multigrade classrooms. Aggressive Behavior, 45, 561570. https://doi.org/10.1002/ab.21851

Rambaran, J. A., Van Duijn, M. A. J., Dijkstra, J. K., \& Veenstra, R. (2020). Stability and change in student classroom composition and its impact on peer victimization. Journal of Educational Psychology, 112, 1677-1691. https://doi.org/10.1037/edu0000438

Ripley, R. M., Snijders, T. A. B., Boda, Z., Vörös, A., \& Preciado, P. (2019). Manual for 
RSiena. University of Oxford: Department of Statistics, Nuffield College.

Rivera, M. T., Soderstrom, S. B., \& Uzzi, B. (2010). Dynamics of dyads in social networks: assortative, relational, and proximity mechanisms. Annual Review of Sociology, 36, 91115. https://doi.org/10.1146/annurev.soc.34.040507.134743

Rodkin, P. C., \& Berger, C. (2008). Who bullies whom? Social status asymmetries by victim gender. International Journal of Behavioral Development, 32, 488-501. https://doi.org/10.1177/0165025408093667

Ruggieri, S., Friemel, T., Sticca, F., Perren, S., \& Alsaker, F. (2013). Selection and influence effects in defending a victim of bullying: The moderating effects of school context. Procedia - Social and Behavioral Sciences, 79, 117-126. https://doi.org/10.1016/j.sbspro.2013.05.060

Rulison, K. L., Gest, S. D., \& Osgood, D. W. (2015). Adolescent peer networks and the potential for the diffusion of intervention effects. Prevention Science, 16, 133-144. https://doi.org/10.1007/s11121-014-0465-3

Sainio, M., Veenstra, R., Huitsing, G., \& Salmivalli, C. (2011). Victims and their defenders: A dyadic approach. International Journal of Behavioral Development, 35, 144-151. https://doi.org/10.1177/0165025410378068

Sainio, M., Veenstra, R., Huitsing, G., \& Salmivalli, C. (2012). Same- and other-sex victimization: Are the risk factors similar? Aggressive Behavior, 38, 442-455. https://doi.org/10.1002/ab.21445

Salmivalli, C. (2010). Bullying and the peer group: A review. Aggression and Violent Behavior, 15, 112-120. https://doi.org/10.1016/j.avb.2009.08.007

Sentse, M., Dijkstra, J. K., Salmivalli, C., \& Cillessen, A. H. N. (2013). The dynamics of friendships and victimization in adolescence: A longitudinal social network perspective. Aggressive Behavior, 39, 229-238. https://doi.org/10.1002/ab.21469 
Sentse, M., Kiuru, N., Veenstra, R., \& Salmivalli, C. (2014). A social network approach to the interplay between adolescents' bullying and likeability over time. Journal of Youth and Adolescence, 43, 1409-1420. https://doi.org/10.1007/s10964-014-0129-4

Shin, H. (2020). The role of perceived bullying norms in friendship dynamics: An examination of friendship selection and influence on bullying and victimization. International Journal of Behavioral Development. https://doi.org/10.1177/0165025419868533

Sijtsema, J. J., Rambaran, J. A., Caravita, S. C. S., \& Gini, G. (2014). Friendship selection and influence in bullying and defending: Effects of moral disengagement. Developmental Psychology, 50, 2093-2104. https://doi.org/10.1037/a0037145

Sijtsema, J. J., Rambaran, J. A., \& Ojanen, T. J. (2013). Overt and relational victimization and adolescent friendships: Selection, de-selection, and social influence. Social Influence, 8 , 177-195. https://doi.org/10.1080/15534510.2012.739097

Sijtsema, J. J., Veenstra, R., Lindenberg, S., \& Salmivalli, C. (2009). Empirical test of bullies' status goals: Assessing direct goals, aggression, and prestige. Aggressive Behavior, 35, 57-67. https://doi.org/10.1002/ab.20282

Snijders, T. A. B., Van de Bunt, G. G., \& Steglich, C. E. G. (2010). Introduction to stochastic actor-based models for network dynamics. Social Networks, 32, 44-60. https://doi.org/10.1016/j.socnet.2009.02.004

Stark, T. H., \& Flache, A. (2012). The double edge of common interest: Ethnic segregation as an unintended byproduct of opinion homophily. Sociology of Education, 85, 179-199. https://doi.org/10.1177/0038040711427314

Tatum, T. G., \& Grund, T. U. (2020). Accusation and confession discrepancies in bullying : Dual-perspective networks and individual-level attributes. Social Networks, 60, 61-70. https://doi.org/10.1016/j.socnet.2019.09.001 
Tolsma, J., Van Deurzen, I., Stark, T. H., \& Veenstra, R. (2013). Who is bullying whom in ethnically diverse primary schools? Exploring links between bullying, ethnicity, and ethnic diversity in Dutch primary schools. Social Networks, 35, 51-61. https://doi.org/10.1016/j.socnet.2012.12.002

Valente, T. W. (2012). Network interventions. Science, 337, 49-53.

Van den Berg, Y. H. M., Segers, E., \& Cillessen, A. H. N. (2012). Changing peer perceptions and victimization through classroom arrangements: A field experiment. Journal of Abnormal Child Psychology, 40, 403-412. https://doi.org/10.1007/s10802-011-9567-6

Van der Ploeg, R., Steglich, C., \& Veenstra, R. (2020). The way bullying works: How new ties facilitate the mutual reinforcement of status and bullying in elementary schools. Social Networks, 60, 71-82. https://doi.org/10.1016/j.socnet.2018.12.006

Veenstra, R., Dijkstra, J. K., \& Kreager, D. A. (2018). Pathways, networks, and norms: A sociological perspective on peer research. In W. M. Bukowski, B. Laursen, \& K. H. Rubin (Eds.), Handbook of peer interactions, relationships, and groups (2nd edition) (pp. 45-63). New York: Guilford.

Veenstra, R., Dijkstra, J. K., Steglich, C., \& Van Zalk, M. H. W. (2013). Network-behavior dynamics. Journal of Research on Adolescence, 23, 399-412. https://doi.org/10.1111/jora.12070

Veenstra, R., Lindenberg, S., Zijlstra, B. J. H., De Winter, A. F., Verhulst, F. C., \& Ormel, J. (2007). The dyadic nature of bullying and victimization: Testing a dual perspective theory. Child Development, 78, 1843-1854. https://doi.org/10.1111/j.14678624.2007.01102.x

Veenstra, R., \& Steglich, C. E. G. (2012). Actor-based model for network and behavior dynamics: A tool to examine selection and influence processes. In B. Laursen, T. D. Little, \& N. A. Card (Eds.), Handbook of developmental research methods (pp. 598- 
618). New York: Guilford.

Verlinden, M., Veenstra, R., Ringoot, A. P., Jansen, P. W., Raat, H., Hofman, A., Jaddoe, V.W.V., Verhulst, F.C. \& Tiemeier, H. (2014). Detecting bullying in early elementary school with a computerized peer-nomination instrument. Psychological Assessment, 26, 628-641. https://doi.org/10.1037/a0035571

Volk, A. A., Dane, A. V, \& Marini, Z. A. (2014). What is bullying? A theoretical redefinition. Developmental Review, 34, 327-343. https://doi.org/10.1016/j.dr.2014.09.001

Warr, M. (2002). Companions in crime: The social aspects of criminal conduct. Cambridge, UK: Cambridge University Press.

Zajonc, R. (1968). Attitudinal effects of mere exposure. Journal of Personality and Social Psychology, 9, 1-27.

Zijlstra, B. J. H., Van Duijn, M. A. J., \& Snijders, T. A. B. (2006). The multilevel p2 model: A random effects model for the analysis of multiple social networks. Methodology, 2, $42-47$. 
Table 11.1. Studies examining network and bullying-related dynamics

\begin{tabular}{|c|c|c|c|c|c|c|c|c|c|}
\hline Reference & Country & $\begin{array}{l}\text { Setting } \\
(\mathbf{N})\end{array}$ & $\begin{array}{c}\text { Sample } \\
\text { Size }\end{array}$ & $\begin{array}{c}\text { Mean } \\
\text { Age }\end{array}$ & $\begin{array}{c}\text { Waves } \\
\text { (Interval) }\end{array}$ & $\begin{array}{l}\text { Network } \\
\text { (Choice) }\end{array}$ & $\begin{array}{l}\text { Behavior } \\
\text { (Reporter) }\end{array}$ & Selection & Influence \\
\hline $\begin{array}{l}\text { Ruggieri et al. } \\
(2013)\end{array}$ & CHE & $\begin{array}{l}\text { Grade } \\
\text { (7) }\end{array}$ & 478 & 13.2 & $2(7)$ & $\begin{array}{l}\text { Hang out with } \\
\text { (unlimited) }\end{array}$ & Defending (S) & $1.12(0.57)$ & $1.94(1.20)$ \\
\hline $\begin{array}{l}\text { Sentse et al. } \\
\text { (2013) }\end{array}$ & USA & $\begin{array}{l}\text { Grade } \\
\text { (2) }\end{array}$ & 480 & 11.5 & $3(12)$ & $\begin{array}{l}\text { Best friend } \\
\text { (unlimited) }\end{array}$ & $\begin{array}{l}\text { Phys. Vict. (S) } \\
\text { Rel. Vict. (S) }\end{array}$ & $\begin{array}{l}\mathbf{0 . 4 1}(\mathbf{0 . 0 4 )} \\
0.20(0.42)\end{array}$ & $\begin{array}{l}1.85(3.12) \\
\mathbf{1 . 4 1 ( 0 . 4 1 )}\end{array}$ \\
\hline $\begin{array}{l}\text { Sijtsema et al. } \\
(2013)\end{array}$ & FIN & $\begin{array}{l}\text { Grade } \\
(4)\end{array}$ & 504 & 12.5 & $3(6)$ & $\begin{array}{l}\text { Best friend } \\
\text { (up to 18) }\end{array}$ & $\begin{array}{l}\text { Overt Vict. (P) } \\
\text { Rel. Vict. (P) }\end{array}$ & $\begin{array}{r}\text { Creation: }-1.10(1.12) \\
\text { Maintenance: } 1.14(1.72) \\
\text { Creation: } 1.46(\mathbf{0 . 4 3}) \\
\text { Maintenance: } 0.10(0.22)\end{array}$ & $\begin{array}{l}6.32(0.89) \\
4.69(0.74)\end{array}$ \\
\hline $\begin{array}{l}\text { Caravita et al. } \\
\text { (2014); Sijtsema } \\
\text { et al. (2014) }\end{array}$ & ITA & $\begin{array}{c}\text { Class } \\
(6)\end{array}$ & 133 & 9.4 & $2(12)$ & $\begin{array}{l}\text { Best friend } \\
\text { (up to 5) }\end{array}$ & $\begin{array}{l}\text { Bullying }(\mathrm{P}) \\
\text { Defending }(\mathrm{P}) \\
\text { Moral Diseng. (P) }\end{array}$ & $\begin{array}{r}\text { Creation: }-0.06(0.05) \\
\text { Maintenance: } 0.09(0.06) \\
\text { Creation: }-0.09(0.07) \\
\text { Maintenance } 0.07(0.07) \\
0.56(0.57)\end{array}$ & $\begin{array}{l}1.13(0.91) \\
0.80(0.55) \\
3.60(2.47)\end{array}$ \\
\hline $\begin{array}{l}\text { Caravita et al. } \\
\text { (2014); Sijtsema } \\
\text { et al. (2014) }\end{array}$ & ITA & $\begin{array}{c}\text { Class } \\
(10)\end{array}$ & 236 & 11.9 & $2(12)$ & $\begin{array}{l}\text { Best friend } \\
\text { (up to 5) }\end{array}$ & $\begin{array}{l}\text { Bullying }(\mathrm{P}) \\
\text { Defending }(\mathrm{P}) \\
\text { Moral Diseng. (P) }\end{array}$ & 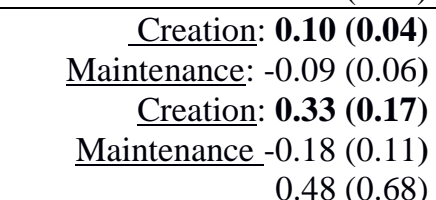 & $\begin{array}{l}1.37(0.59) \\
2.15(0.64) \\
7.49(2.56)\end{array}$ \\
\hline $\begin{array}{l}\text { Huitsing et al. } \\
\text { (2014) }\end{array}$ & NLD & $\begin{array}{l}\text { School } \\
\text { (3) }\end{array}$ & 354 & 10 & $3(12)$ & Defending & $\begin{array}{l}\text { Bullying (D) } \\
\text { Victimization (D) }\end{array}$ & $\begin{array}{r}0.40(0.00) \\
\chi^{2}=29 \\
\chi^{2}=20\end{array}$ & $\begin{array}{r}\chi^{2}=80 \\
\chi^{2}=30\end{array}$ \\
\hline $\begin{array}{l}\text { Sentse et al. } \\
\text { (2014) }\end{array}$ & FIN & $\begin{array}{l}\text { Class } \\
(686)\end{array}$ & 9183 & 14 & $3(6)$ & $\begin{array}{l}\text { Liked most } \\
\text { (unlimited) }\end{array}$ & Bullying $(\mathrm{P})$ & $0.36(0.10)$ & $5.08(0.79)$ \\
\hline $\begin{array}{l}\text { Lodder et al. } \\
\text { (2016) }\end{array}$ & NLD & $\begin{array}{l}\text { Grade } \\
(4)\end{array}$ & 543 & 15.8 & $2(5)$ & $\begin{array}{l}\text { Closest friend } \\
\text { (up to 20) }\end{array}$ & Victimization (S) & $0.43(0.20)$ & $2.29(0.93)$ \\
\hline $\begin{array}{l}\text { Merrin et al. } \\
(2018)\end{array}$ & USA & $\begin{array}{l}\text { School } \\
\text { (1) }\end{array}$ & 190 & 13.5 & $3(6)$ & $\begin{array}{l}\text { Best friend } \\
\text { (up to 8) }\end{array}$ & $\begin{array}{l}\text { Bullying (S) } \\
\text { Homophobic (S) }\end{array}$ & $\begin{array}{l}0.14(0.38) \\
\mathbf{1 . 3 7}(\mathbf{0 . 5 7})\end{array}$ & $\begin{array}{l}1.73(1.81) \\
\mathbf{2 . 1 4}(\mathbf{1 . 0 4})\end{array}$ \\
\hline $\begin{array}{l}\text { Berger. C. et al. } \\
\text { (2019) }\end{array}$ & CHL & $\begin{array}{c}\text { Class } \\
\text { (5) }\end{array}$ & 185 & 10 & $3(12)$ & $\begin{array}{l}\text { Best friend } \\
\text { (unlimited) }\end{array}$ & Victimization (S) & $0.04(0.05)$ & $0.25(0.33)$ \\
\hline $\begin{array}{l}\text { Rambaran et al. } \\
(2020)\end{array}$ & NLD & $\begin{array}{c}\text { Class } \\
(19)\end{array}$ & 481 & 10 & $3(6)$ & $\begin{array}{l}\text { Best friend } \\
\text { (unlimited) }\end{array}$ & $\begin{array}{l}\text { Bullying (D) } \\
\text { Victimization (D) }\end{array}$ & $\begin{array}{l}\mathbf{0 . 4 1}(\mathbf{0 . 1 7}) \\
0.06(0.10)\end{array}$ & $\begin{array}{l}\mathbf{0 . 7 4}(\mathbf{0 . 1 4}) \\
0.03(0.12)\end{array}$ \\
\hline $\begin{array}{l}\text { Shin. H. } \\
\text { (2020) }\end{array}$ & KOR & $\begin{array}{l}\text { Class } \\
(26)\end{array}$ & 736 & 11.5 & $2(5)$ & $\begin{array}{l}\text { Hang out with } \\
\text { (unlimited) }\end{array}$ & $\begin{array}{l}\text { Bullying }(\mathrm{P}) \\
\text { Victimization }(\mathrm{P})\end{array}$ & $\begin{array}{l}0.01(0.25) \\
1.62(0.56)\end{array}$ & $\begin{array}{l}1.08(0.30) \\
1.68(0.44)\end{array}$ \\
\hline
\end{tabular}

Note. Significant effects $(p<.05)$ in bold. Interval in months. Reporter: $\mathrm{S}=$ Self-report; $\mathrm{P}=$ Peer nominations; $\mathrm{D}=\mathrm{Dyadic}$ nominations.

Country abbreviations: $\mathrm{CHE}=$ Switzerland CHL $=$ Chile; FIN $=$ Finland; ITA $=$ Italy; KOR $=$ South Korea; NLD $=$ the Netherlands; USA =

United States of America. 
Figure 11.1. Representation of selection and influence effects.

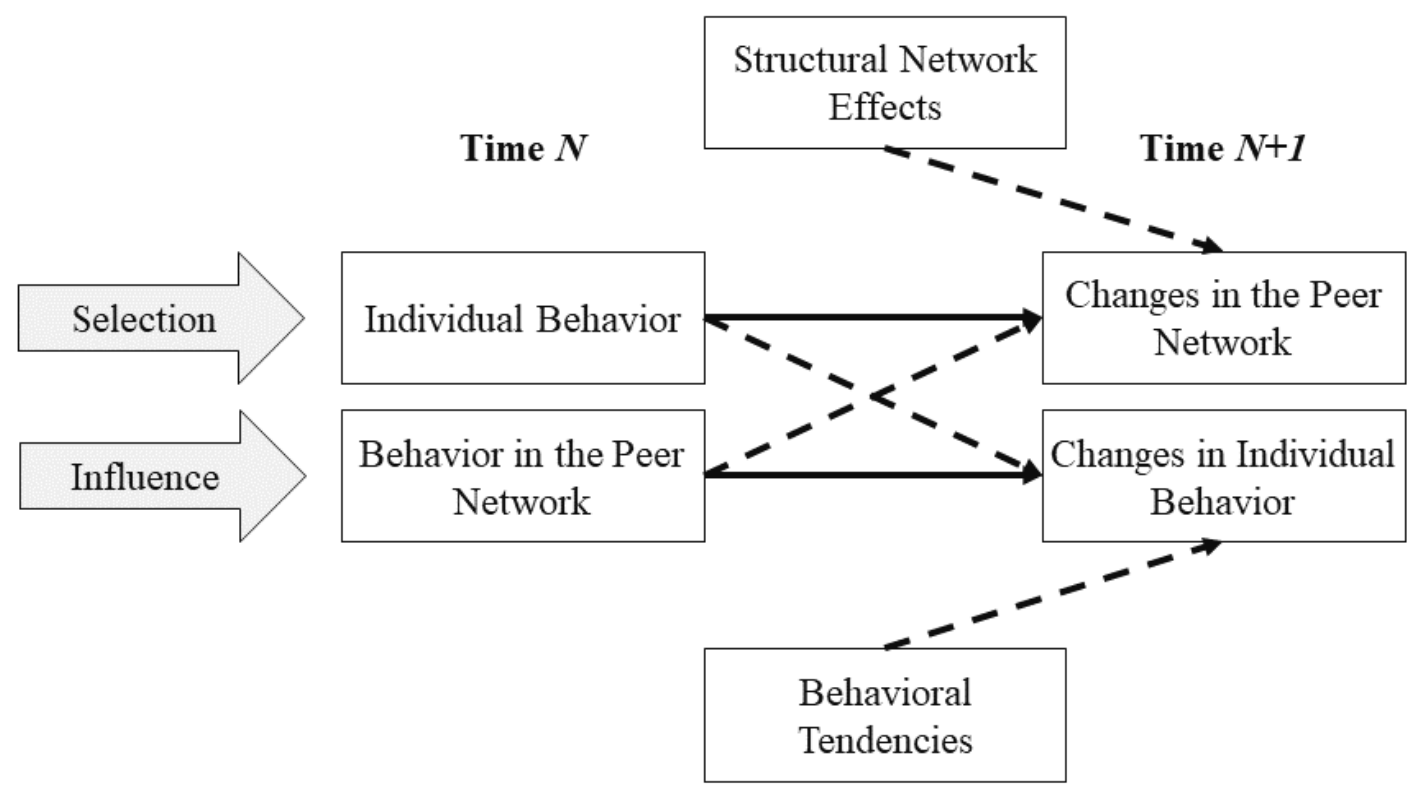

Note. The solid lines express that individuals can change their peer network (selection) and behavior (influence) between two time points. The dashed lines express that selection and influence effects are estimated while the network structure and behavior at Time 1, the structural network effects (e.g., reciprocity, transitivity), and behavioral tendencies are taken into account. 
Figure 11.2. Victim similarity: The interplay between bullying and defending networks.

Time $N$

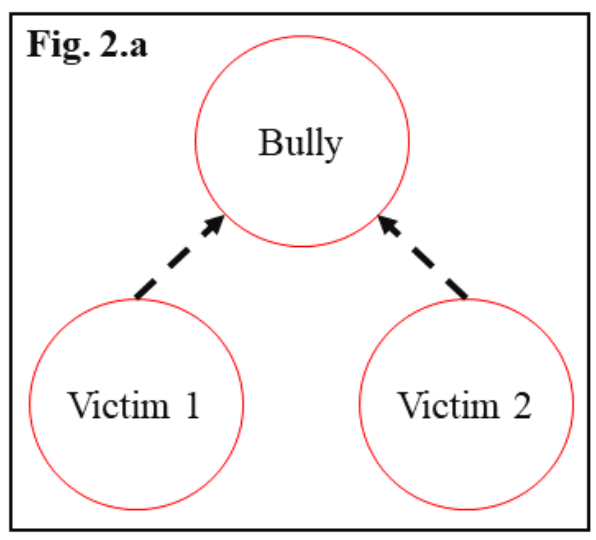

Fig. 2.b

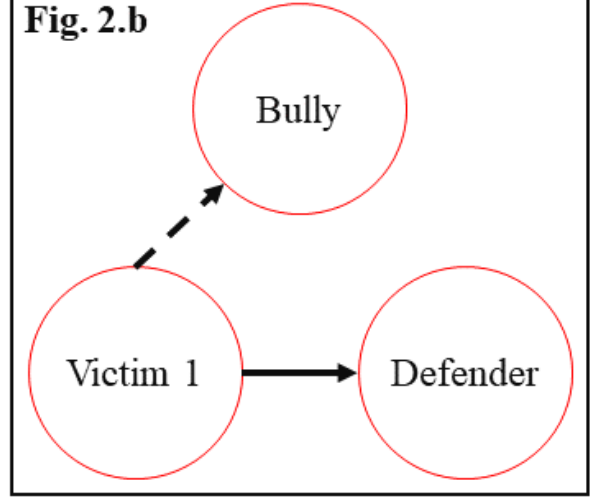

Time $N+1$

\section{Victim similarity:}

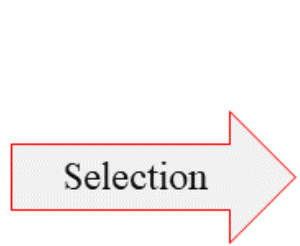

Influence

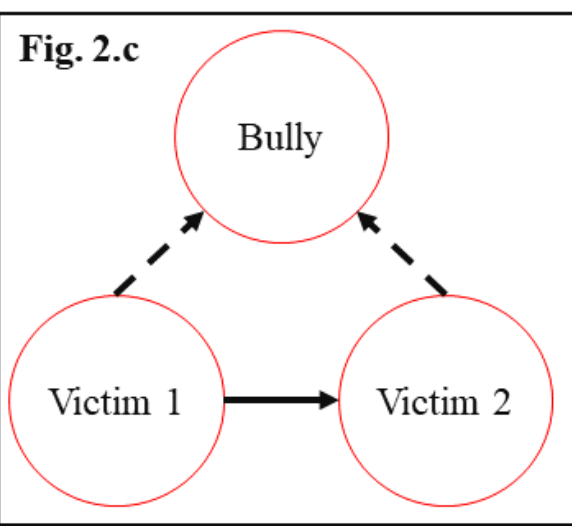

- - $\rightarrow$ Bullying ("By whom are you victimized?")

$\longrightarrow$ Defending ("By whom are you defended?") 
Figure 11.3. Bully similarity: The interplay between bullying and defending networks.

Time $N$

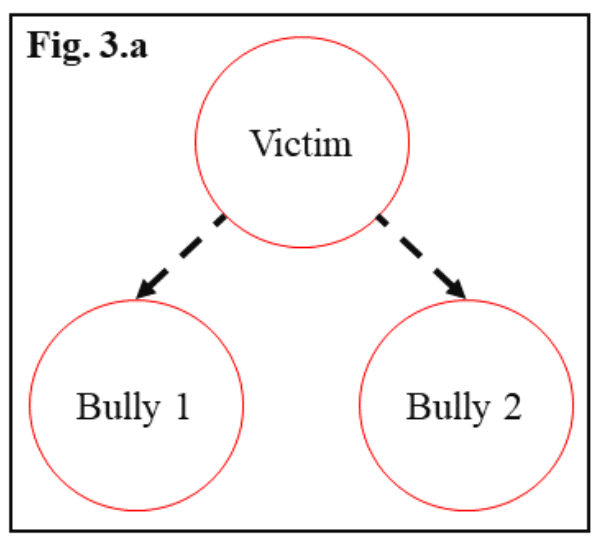

Fig. 3.b

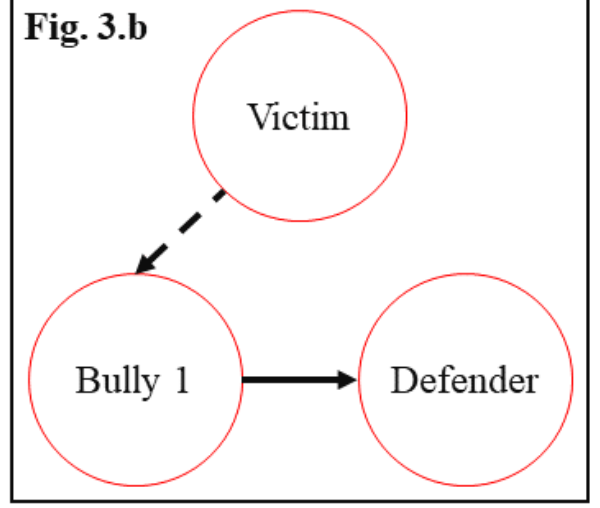

Time $N+1$

\section{Bully similarity:}

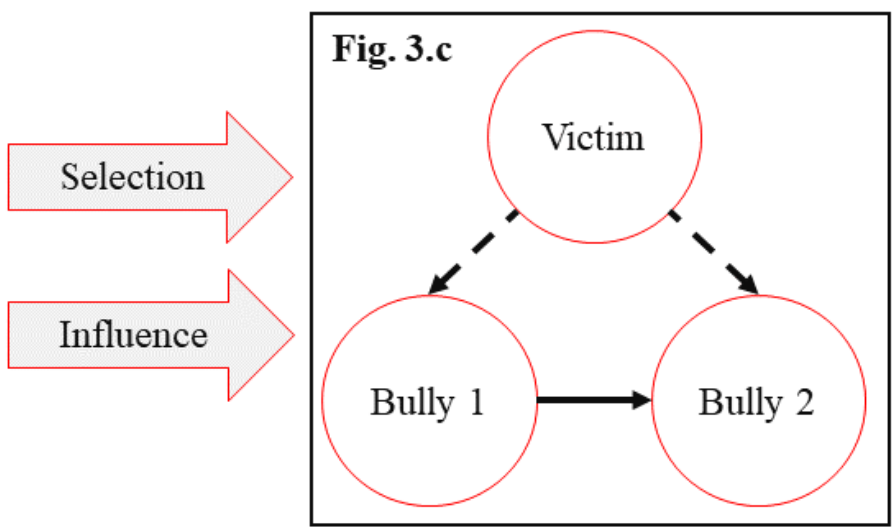

- $\rightarrow$ Bullying ("By whom are you victimized?")

Defending ("By whom are you defended?") / Friendships

("Who are your best friends") 